Original Research Article

\title{
Community pharmacists' perception of and practice with drug package inserts in UAE
}

\author{
Suleiman I. Sharif*, Jalal Edien M.W. Alkharrat, Lubna A. Khaled, \\ Nour Elhouda Arafeh, Sana Y. Birawi
}

\author{
Department of Pharmacy \\ Practice and \\ Pharmacotherapeutics, College \\ of Pharmacy, University of \\ Sharjah, P. O. Box 27272, \\ Sharjah, United Arab Emirates
}

Received: 06 December 2016

Accepted: 27 December 2016

\section{*Correspondence to: \\ Dr. Suleiman I. Sharif, \\ Email: sharifsi@sharjah.ac.ae}

Copyright: () the author(s), publisher and licensee Medip Academy. This is an openaccess article distributed under the terms of the Creative Commons Attribution NonCommercial License, which permits unrestricted noncommercial use, distribution, and reproduction in any medium, provided the original work is properly cited.

\begin{abstract}
Background: Written information in drug package inserts (DPIs) is important source of information for doctors and pharmacists. Objectives: The present study was undertaken to evaluate the knowledge, perception and practice of community pharmacists with information in the DPIs, and their views on their usefulness.
\end{abstract}

Methods: Seventy five pre-piloted questionnaires were distributed to community pharmacists in the United Arab Emirates. The questionnaire included questions covering demographics of pharmacists and whether they read and rely on DPI as a source of information. Pharmacists were also asked to evaluate and categorize DPI information with respect to the ease for patient use. The data were analyzed and are expressed as frequency and percentage.

Results: The response rate was $90.7 \%$. The majority $(52,76.5 \%)$ of pharmacists were in the age range of 20-39 years, with bachelor of pharmacy degree $(50,73.5 \%)$ and having $1-10$ years of practice experience $(48,70.6 \%)$. Two thirds of the respondents obtained their degree outside the UAE. The majority $(60,88.2 \%)$ of pharmacists read the DPIs of prescription and OTC drugs, for all the information and think it is useful (67, 98.5\%). Most participants think DPI is useful to patients and advise them to read it. The majority $(49,72.1 \%)$ of pharmacists believe that DPI are clear to read but their content should be shorter $(46,67.6 \%)$ and limited to the most important information $(51,75 \%)$. More pharmacists with a degree from outside UAE do not read the DPIs ( $\mathrm{p}<0.003$ ), and find DPIs easily understood ( $\mathrm{P}<0.008)$. More pharmacists with 1-5 years' experience advise their patients to read the DPIs $(\mathrm{P}<0.033)$.

Conclusions: Our findings suggest that there is a need for improving the content of drug package inserts to provide the necessary information required not only for health care professionals but also patients to further enhance their acceptance of and compliance with their medications.

Keywords: Community pharmacists, Drug package inserts, Knowledge, Perception, Practice

\section{INTRODUCTION}

Drug package inserts or drug leaflets included in the package of prescription and over-the counter (OTC) drugs are the most frequently and readily available drug information used by patients, physicians and pharmacists. $^{1-3}$ Many studies have demonstrated that reading the package insert plays a role in increasing patient compliance, satisfaction, and ability to follow instructions. ${ }^{4-6}$ Verbal information alone may not improve patient's health literacy of his condition and medication. This is due to the fact that verbal information may not be well understood, misunderstood or not easily recalled after leaving the hospital, clinic or pharmacy. It has been stressed that a combination of both verbal and written information markedly increases knowledge and compliance. ${ }^{7-9}$ Drug package inserts provide useful, clear, and comprehensive information on the medication to both pharmacists and patients. ${ }^{10,11}$ Thus pharmacists being front line health care professionals should use the inserts 
as source of information and advise their patients to read the inserts. Package inserts help pharmacists to counsel the patients about their medications by supporting and reinforcing the verbal information. It helps them to get updated information about new drugs and to keep as their on-going references. ${ }^{12}$ The aim of the present study is to assess the attitude and practice of community pharmacists towards drug package inserts.

\section{METHODS}

A questionnaire- based cross sectional study was conducted between September and November 2016. The questionnaire was developed to evaluate the knowledge, attitude and practice of community pharmacists toward drug package inserts (DPIs) and the most important information for patients and characteristics of understandable and legible DPI. The questionnaire was distributed to practicing community pharmacists. Questions were mainly evaluating DPI content, usefulness and whether DPI are understood by patients ability to the patient from professional point of view. The questionnaire included questions covering demographic characteristics of the pharmacists. These include age, gender, type of pharmacy degree and place where it was obtained (UAE or outside UAE), years of practice and average number of prescriptions dispensed per day. Pharmacists were also asked if they read and rely on DPI information and what other sources they use to obtain information. The pharmacists were also asked to evaluate and categorize DPI information and content with respect to the ease for patient use.

\section{Statistical analysis}

The participants' responses were encoded, and the data were analysed using Statistical Package for the Social Sciences (SPSS version 20, Chicago, IL, USA). The questions were in different distinct formats. Chi-squared test was used to identify any significant difference among the participants' responses regarding certain statements in the questionnaire with a significance level of $\mathrm{P}<0.05$.

\section{RESULTS}

We distributed 75 questionnaires and received completed 68 surveys producing a response rate of $90.7 \%$. Demographic characteristics of community pharmacists are shown in Table 1. The majority $(52,76.5 \%)$ of pharmacists were in the age range of 20-39 years, with traditional pharmacy degree (B. Pharm., 50,73.5\%) and having 1-10 years of practicing experience $(48,70.6 \%)$. Only small number of pharmacists had a Pharm. D. degree. About two thirds of the respondents obtained their degree outside the UAE. Average number of prescriptions dispensed per day is shown in Table 2 and was reported to be less than $10(11,16.2 \%), 10-14(17$, $25 \%), 15-19(10,14.7 \%), 20-29(12,17.6 \%)$ and 30 and more $(18,26.5 \%)$. The average number of consultation without prescription ranged from as low as 1-4 to as high as more than 15 . The majority $(44,64.7 \%)$ reported having daily 10 to more than 15 consultations.

\section{Table 1: Demographic characteristics of community pharmacists.}

\begin{tabular}{|ll|}
\hline Criteria & Frequency $(\%), \mathbf{n}=\mathbf{6 8}$ \\
\hline Age & \\
$20-29$ & $32(47.1 \%)$ \\
$30-39$ & $20(29.4 \%)$ \\
$40-49$ & $10(14.7 \%)$ \\
$50-59$ & $5(7.4 \%)$ \\
More than 60 & $1(1.5 \%)$ \\
\hline Gender & \\
Male & $37(54.4 \%)$ \\
Female & $31(45.6 \%)$ \\
\hline Degree & \\
B. pharm & $50(73.5 \%)$ \\
Pharm D & $15(22.1 \%)$ \\
Master & $3(4.4 \%)$ \\
Ph.D. & 0 \\
\hline Obtained in : & \\
UAE & $23(33.8 \%)$ \\
Outside UAE & $45(66.2 \%)$ \\
\hline Years of practicing pharmacy \\
\hline $1-5$ & $27(39.7 \%)$ \\
$6-10$ & $21(30.9 \%)$ \\
$11-15$ & $10(14.7 \%)$ \\
$16-20$ & $5(7.4 \%)$ \\
20 and more & $5(7.4 \%)$ \\
\hline
\end{tabular}

Table 2: Daily average number of encounters/day and patients' consultations and enquires received by community pharmacists.

\begin{tabular}{|lc|}
\hline Daily prescription/consultations & $\begin{array}{c}\text { Frequency } \\
(\%), \mathbf{n = 6 8}\end{array}$ \\
\hline Average number of prescriptions/day & $11(16.2 \%)$ \\
\hline$<10$ & $17(25.0 \%)$ \\
$10-14$ & $10(14.7 \%)$ \\
$15-19$ & $12(17.6 \%)$ \\
$20-29$ & $18(26.5 \%)$ \\
30 and more & $12(17.6 \%)$ \\
\hline Average number of consultation without prescription \\
\hline $1-4$ & $12(17.6 \%)$ \\
$5-9$ & $17(25.0 \%)$ \\
$10-15$ & $27(39.7 \%)$ \\
More than 15 & \\
\hline Do you receive any enquiries about information in \\
package insert? & $52(76.5 \%)$ \\
\hline Yes & $16(23.5 \%)$ \\
\hline No & $37(54.4 \%)$ \\
\hline What the most common enquiries are about? \\
\hline All information & $17(25.0 \%)$ \\
Drug dosage form and compositions & $14(20.6 \%)$ \\
\hline Mechanism of action and adverse & \\
effects &
\end{tabular}


Again, 52 (76.5\%) pharmacists stated that they receive daily enquiries about information in the package inserts of patient's medication (Table 2). Enquiries focus on all information $(37,54.4 \%)$, drug dosage and composition $(17,25 \%)$ and mechanism of action and adverse effects $(14,20.6 \%)$. Table 3 shows that the majority $(60,88.2 \%)$ of pharmacists read the package inserts of both $(40$, $58.8 \%)$ prescription and OTC drugs, for all $(59,86.8 \%)$ the written information and think it is useful $(67,98.5 \%)$.

Table 3: Attitude of community pharmacists towards drug package inserts.

\begin{tabular}{|ll|}
\hline Pharmacist's response & $\begin{array}{l}\text { Frequency } \\
(\%), \mathrm{n}=68\end{array}$ \\
\hline Do you read package insert? & $60(88.2 \%)$ \\
Yes & $8(11.8 \%)$ \\
No & \\
\hline Do you think package inserts are useful to you as a \\
pharmacist? & $67(98.5 \%)$ \\
\hline Yes & $1(1.5 \%)$ \\
No & \\
\hline Which section of package insert do you consider useful to \\
you? & $59(86.8 \%)$ \\
\hline All information & $1(1.5 \%)$ \\
Active ingredients & $5(7.4 \%)$ \\
Dosage regimen & 0 \\
Mechanism of action & 0 \\
Toxicity & $1(1.5 \%)$ \\
Precautions and contraindications & 0 \\
Adverse effects & $1(1.5 \%)$ \\
Drug interactions & 0 \\
Expiry date & 0 \\
Storage & $1(1.5 \%)$ \\
No response & \\
\hline What package inserts do you usually read? & \\
\hline Prescription drug & $16(23.5 \%)$ \\
OTC drugs & $4(5.9 \%)$ \\
Both & $40(58.8 \%)$ \\
No response & $8(11.8 \%)$ \\
\hline When reading package insert I focus on & \\
\hline All information & $37(54.4 \%)$ \\
Drug dosage form and & \\
composition & $18(26.5 \%)$ \\
Mechanism of action and & \\
adverse effect & $5(7.4 \%)$ \\
No response & $8(11.8)$ \\
\hline I do not read package insert because & \\
\hline I know the information & $5(7.4 \%)$ \\
I rely on medical representative & $4(5.9 \%)$ \\
Package insert is not easy to read & 0 \\
Small print & 0 \\
Difficult technical terms & 0 \\
I am drug expert & 0 \\
No response & $59(86.8 \%)$ \\
\hline What are your sources of information since you do not read \\
package inserts? & \\
\hline Internet & \\
Text books & \\
BNF & \\
Own knowledge & \\
No response & \\
\hline & \\
\hline
\end{tabular}

Most participants $(57,83.8 \%)$ think that the package insert is useful to patients and more than half $(39,57.4 \%)$ of the participants advise their patients to read it (Table $4)$. However, the majority $(56,82.4 \%)$ of pharmacists agreed that patients may decline to use the medicine if they read the side effects part. On the other hand, Table 5 show that when asked about their views of the usual drug package inserts, the majority $(49,72.1 \%)$ of pharmacists believe that although they are clear for easy reading and beneficial to patients $(51,75 \%)$ but they could be confusing to patients, their content should be shorter (46, $67.6 \%$ ), limited to the most important information (51, $75 \%$ ) and written in English and Arabic (41, 60.3\%).

Table 4: Views of community pharmacists regarding their advice to patients on drug package inserts.

\begin{tabular}{|lc|}
\hline Question & $\begin{array}{c}\text { Frequency } \\
(\%), \mathbf{n}=68\end{array}$ \\
\hline Do you think package inserts are useful to patients? \\
\hline Yes & $57(83.8 \%)$ \\
No & $11(16.2 \%)$ \\
\hline Do you advise your patients to- & $39(57.4 \%)$ \\
\hline Read the package insert? & $29(42.6 \%)$ \\
\hline Not to read the package insert? & $17(25 \%)$ \\
\hline What section do you advise your patients to read? \\
\hline All information & $20(29.4 \%)$ \\
Drug dosage form and composition & $2(2.9 \%)$ \\
Mechanism of action and adverse & \\
effects & $29(42.6 \%)$ \\
No response & \\
\hline Do you think patients may decline to use the medicine \\
if they read the side effects part? \\
\hline Yes \\
No
\end{tabular}

There was no association between the average number of prescriptions dispensed per day or the type of pharmacy degree and any of the pharmacists' demographics. However, the number of pharmacists with a degree obtained outside UAE was significantly higher than those with a UAE degree in not reading the DPIs ( $p<0.003$ ), what they advise their patients to read in the DPI ( $P$ $<0.024)$ and the DPIs are easily understood ( $\mathrm{P}<0.008)$. We have also observed that more pharmacists with a practicing experience of 1-5 years tend to advise their patients to read the DPIs (P, 0.033).

\section{DISCUSSION}

Drug package inserts or drug leaflets included in the package of prescription and over-the counter (OTC) drugs provide the prescribing physician, the dispensing pharmacist and the patient with the most important information about the medication. Verbal information given by the doctor is limited by the pressure of time to dose and side effects. On the other hand, information given by the community pharmacist is concentrated mainly on dose and frequency of administration. 
Table 5: General views of community pharmacists on drug package inserts.

\begin{tabular}{|c|c|}
\hline Pharmacist's response & $\begin{array}{l}\text { Frequency } \\
(\%), n=68\end{array}$ \\
\hline \multicolumn{2}{|c|}{$\begin{array}{l}\text { In what language do you prefer package insert to be } \\
\text { written? }\end{array}$} \\
\hline English & $25(36.8 \%)$ \\
\hline Arabic & $2(2.9 \%)$ \\
\hline Both languages & $41(60.3 \%)$ \\
\hline \multicolumn{2}{|c|}{$\begin{array}{l}\text { Do you think package insert give relevant } \\
\text { information? }\end{array}$} \\
\hline Yes & $62(91.2 \%)$ \\
\hline No & $5(7.4 \%)$ \\
\hline No response & $1(1.5 \%)$ \\
\hline \multicolumn{2}{|c|}{ How do you categorize legibility of package inserts } \\
\hline Legible (clear) & $49(72.1 \%)$ \\
\hline Illegible (not clear) & $18(26.5 \%)$ \\
\hline No response & $1(1.5 \%)$ \\
\hline \multicolumn{2}{|c|}{$\begin{array}{l}\text { How do you categorize understandability of package } \\
\text { inserts for patients? }\end{array}$} \\
\hline Easy & $30(44.1 \%)$ \\
\hline Difficult & $38(55.9 \%)$ \\
\hline \multicolumn{2}{|c|}{$\begin{array}{l}\text { Do you think that package inserts are confusing to the } \\
\text { patient? }\end{array}$} \\
\hline Yes & $49(72.1 \%)$ \\
\hline No & $18(26.5 \%)$ \\
\hline No response & $1(1.5 \%)$ \\
\hline \multicolumn{2}{|c|}{$\begin{array}{l}\text { How do you categorize usefulness of package insert } \\
\text { for patients? }\end{array}$} \\
\hline Beneficial & $51(75 \%)$ \\
\hline Not beneficial & $17(25 \%)$ \\
\hline \multicolumn{2}{|c|}{$\begin{array}{l}\text { Do you think the content of package insert should be } \\
\text { shorter? }\end{array}$} \\
\hline Yes & $46(67.6 \%)$ \\
\hline No & $22(32.4 \%)$ \\
\hline \multicolumn{2}{|c|}{$\begin{array}{l}\text { Do you think content should be limited to the most } \\
\text { important information? }\end{array}$} \\
\hline Yes & $51(75 \%)$ \\
\hline No & $17(25 \%)$ \\
\hline
\end{tabular}

Such verbal information although minimal but at risk of being misunderstood, or forgotten particularly when multi drugs are prescribed to the patient. Therefore, it is important if such information is supplemented with written ones. It has been shown that a combination of both verbal and written information significantly improves patients' knowledge and compliance. ${ }^{7-10}$ In the present study, most community pharmacists read DPIs and think of them as a useful primary source of information not only for prescription drugs but also for OTC drugs. Surprisingly and with the exception of one pharmacist who uses in addition the BNF as a source of information, the rest of participants rely only on DPIs for information. Various studies showed that community pharmacists use also other sources of information beside DPIs. ${ }^{13,14}$ Only very few pharmacists do not read DPIs because they rely on the information provided by the medical representatives or they know the information.
Such excuses may not be valid since the pharmacist would be missing up-dated information and also because, in most cases, medical representatives provide biased information in order to promote their products. Our results demonstrated that more than half the community pharmacists advise their patients to read DPIs. However, the majority think that patients may not use the medication if they read the section on side effects. This again stresses on the role of the pharmacist to clarify such a drawback by elaborating on the side effects that the patient is most likely to experience and how to deal with it. DPIs, in addition to their impact on increasing patient's knowledge, compliance and satisfaction provide easily accessible information to patients about their medications. ${ }^{7,13,15}$ Our results indicated that the majority of community pharmacists believe that although DPIs are useful to patients but they may confuse patients and suggest that DPIs should be shorter in length than usual and limited to the most important information needed by patients. This is in harmony with the suggested report on how improving DPI typography will improve legibility for easy comprehension and understanding by lay patients. $^{13}$

\section{CONCLUSION}

Our findings suggest that there is a need for improving the content of drug package inserts to provide the necessary information required not only by health care professionals but also by patients to further enhance their acceptance of and compliance with their medications. Community pharmacists are encouraged to become familiar with the structure and contents of the DPI and they should practice more informative counselling through revising DPI with their patients.

\section{ACKNOWLEDGEMENTS}

The authors wish to thank all the community pharmacists who willingly participated in the survey. Special thanks are also due to Prof. Abduelmola R. Abduelkarim for his invaluable help with the statistical analysis.

\section{Funding: No funding sources}

Conflict of interest: None declared

Ethical approval: The study was approved by the Institutional Ethics Committee

\section{REFERENCES}

1. Regner MJ, Hermann F, Ried LD. Effectiveness of a printed leaflet for enabling patients to use digoxin side-effect information. Drug Intell Clin Pharm. 1987;21(2):200-4.

2. Mottram DR, Reed C. Comparative evaluation of patient information leaflets by pharmacists, doctors and the general public. J Clin Pharm Ther. 1997;22(2):127-34. 
3. Fuchs J, Hippius M, Schaefer M. Analysis of German package inserts. Int $\mathbf{J}$ Clin Pharmacol Ther. 2006;44(1):8-13.

4. Gibbs, S, Waters, WE, George, CF. The benefits of Prescription Information Leaflets (1). $\mathrm{Br} \mathrm{J}$ Clin Pharmacol. 1989;27:723-39.

5. Gibbs S, Waters WE, George CF. Prescription Information leaflets, a national survey. J R Soc Med. 1990;83:292-7.

6. Weitbrecht WU, Vosskämper C. Influence of the drug package information paper on compliance of neurological and psychiatric outpatients. Fortschritte der Neurologie-Psychiatrie. 2002;70(4):178-84.

7. Vander Stichele RH, Van Dierendonck A, De Vooght G, Reynvoet B, Lammertyn J. Impact of benefit messages in patient package inserts on subjective drug perception. Drug Inform J. 2002;26:201-8.

8. Little P, Griffin S, Kelly J, Dickson N, Sadler C. Effect of educational leaflets and questions on knowledge of contraception in women taking the combined contraceptive pill: randomized controlled trial. BMJ. 1998;316:1948-52.

9. Myers ED, Calvert EJ. Information, compliance and side-effects: a study of patients on antidepressant medication. Br J Clin Pharmacol. 1984;17(1):21-5.

10. Cohen, JS. Dose discrepancies between physicians' desk reference and the medical literature and their possible role in the high incidence of dose- related adverse drug events. Arch Intern Med. 2001;161:95764.

11. Hassali MA, Khan TM, Shafie AA. Use of drug information resources by the community pharmacist in Penang, Malaysia. Inform Prim Care. 2010;18(3):213-6.

12. Cheraghali AM, Idries AM. Availability, affordability, and prescribing pattern of medicines in Sudan. Pharm World Sci. 2009;31(2):209-15.

13. Diobi K, Fakeye TO, Adisa R. Community Pharmacists' Perception of the Relevance of Drug Package Insert as Source of Drug Information in Southwestern Nigeria. Tropi. J. Pharmaceut Res. 2013;12(3):439-43.

14. Zehnder S, Beutler M, Bruppacher R, Ehrenhöfer T, Hersberger KE. Needs and use of drug information sources in community pharmacies: a questionnaire based survey in German-speaking Switzerland. Pharm World Sci. 2004;26(4):197-202.

15. Shrank WH, Avorn J. Educating patients about their medications: the potential and limitations of written drug information. Health Aff (Millwood). 2007;26(3):731-40.

Cite this article as: Sharif SI, Alkharrat JEMW, Khaled LA, Arafeh NE, Birawi SY. Community pharmacists' perception of and practice with drug package inserts in UAE. Int J Basic Clin Pharmacol 2017;6:246-50. 